\title{
Development of alveolar-pleural fistula during hepatectomy \\ - A case report -
}

Received January 21, 2018

Revised 1st, February 28, 2018 2nd, April 9, 2019

Accepted April 16, 2019

\section{Corresponding author}

Ji Yeon Kim, M.D., Ph.D.

Department of Anesthesiology and Pain Medicine, Ilsan Paik Hospital, Inje University College of Medicine, 170 Juhwa-ro, Ilsanseo-gu, Goyang 10380, Korea

Tel: 82-31-910-7160

Fax: 82-31-910-7184

E-mail: jy67925@naver.com

ORCID

https://orcid.org/0000-0002-4686-5638

\section{Jun Hyun Kim, Sunghyeok Park, and Ji Yeon Kim}

Department of Anesthesiology and Pain Medicine, Ilsan Paik Hospital, Inje University College of Medicine, Goyang, Korea

Background: An Alveolar-pleural fistula is communication between the alveoli and the pleural space that may result in intractable pneumothorax, severe infection, respiratory failure, physical weakness, and even death.

Case: A 70-year-old male underwent right hepatectomy with a cystic mass of the liver. During the operation, peak airway pressure abruptly increased and a serous fluid was regurgitated through the endotracheal tube. Lung isolation was immediately performed with a double-lumen endotracheal tube. Approximately $1,000 \mathrm{ml}$ of exudate was drained through endotracheal tube. Thoracostomy was performed at right lung. Analysis of fluid from endotracheal tube and pleural effusion consistent with parapneumonic effusion.

Conclusions: We presented a case of alveolar-pleural fistula caused by pneumonia presenting with massive exudate fluid regurgitated from the endotracheal tube that was managed with bronchial suction, lung isolation, and thoracostomy and improved without surgical repair of the fistula.

Keywords: Fistula; Hepatectomy; One lung ventilation; Pleural effusion.
An Alveolar-pleural fistula (APF) is communication between the alveoli and the pleural space that may result in intractable pneumothorax, severe infection, respiratory failure, physical weakness, and even death $[1,2]$.

APF is usually not visible on bronchoscopy and diagnosed clinically $[2,3]$. In addition, APF rarely requires surgical intervention. However, when conservative treatment fails, interventions such as hydrogel application, blood patch, unidirectional valve and surgical repair are required [4-7].

We report a case of APF presenting with massive fluid regurgitated from an endotracheal tube during general anesthesia which was managed with bronchial suction, lung isolation and thoracostomy.

\section{CASE REPORT}

A 70-year-old male $(170 \mathrm{~cm}, 59 \mathrm{~kg})$ was admitted for a cystic mass $(10.4 \times 7.9 \times 7.6 \mathrm{~cm})$ of the liver and decided to undergo right hepatectomy. The patient had a medical history of hypertension and diabetes mellitus. Pre-operative transthoracic echocardiography revealed a left ventricular ejection fraction of $44 \%$ and severe hypokinesia of the left ventricle. Coronary angiography showed no significant stenosis. Pulmonary function tests demonstrated a restrictive ventilation defect. Positron emission tomography-computed tomography (PET-CT) revealed pleural effusion and consolidation in the right lower lobe (Fig. 1). Laboratory findings were as follows: hemoglobin, $12.9 \mathrm{~g} / \mathrm{dl}$, white blood cell, 7,100

This is an Open Access article distributed under the terms of the Creative Commons Attribution Non-Commercial License (http://creativecommons.org/licenses/by-nc/4.0) which permits unrestricted non-commercial use, distribution, and reproduction in any medium, provided the original work is properly cited. 


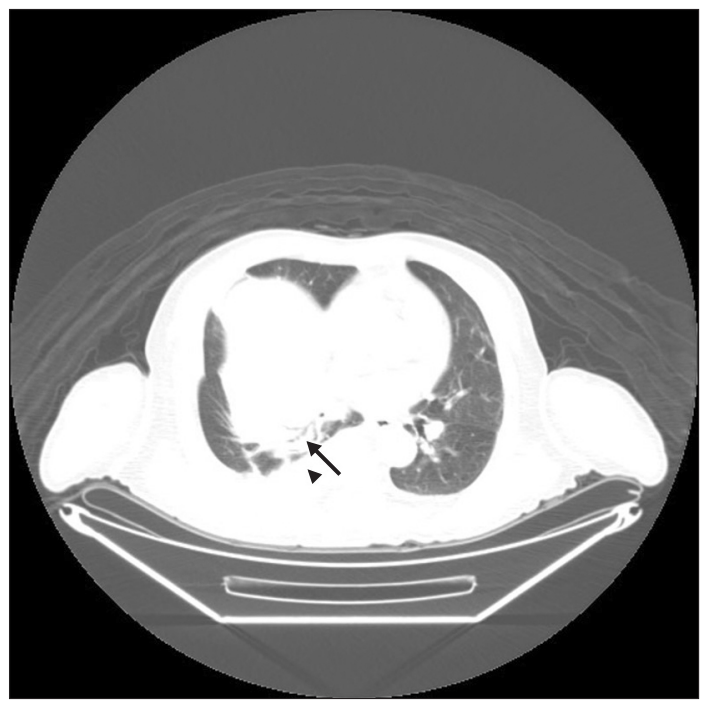

Fig. 1. Pleural effusion and consolidation in pre-operative computed tomography (arrowhead: pleural effusion, arrow: consolidation).

/ $\mu \mathrm{l}$, platelet, 339,000 / $\mu \mathrm{l}$, C-reactive protein, $11.1 \mathrm{mg} / \mathrm{dl}$.

The patient's vital signs were stable prior to general anesthesia. General anesthesia was induced with $50 \mathrm{mg}$ of propofol and rocuronium $50 \mathrm{mg}$ and maintained with $0.2 \mu \mathrm{g} / \mathrm{kg} /$ min of remifentanil and $5 \mathrm{vol} \%$ of desflurane. Tidal volume and respiration rate were set to $400 \mathrm{ml}$ and 13 times/min, espectively. Positive end-expiratory pressure of $5 \mathrm{cmH}_{2} \mathrm{O}$ was applied, and peak inspiratory pressure (PIP) was $20 \mathrm{cmH}_{2} \mathrm{O}$.

At four hours after the beginning of the operation, PIP abruptly increased to $32 \mathrm{cmH}_{2} \mathrm{O}$ and a large amount of serous fluid was regurgitated through the endotracheal tube (ETT) (Figs. 2 and 3). However, hypoxia did not occur at $\mathrm{FiO}_{2}$ 0.5. $\mathrm{PaO}_{2}$ and $\mathrm{PaCO}_{2}$ were within normal range and oxygen saturation was $100 \%$ during the entire intra-operative period. The endotracheal tube was exchanged for a $35 \mathrm{Fr}$ left doublelumen endotracheal tube (DLT) and tracheal suction was performed continuously. Approximately 1,000 $\mathrm{ml}$ of yellowish fluid was regurgitated through the right side lumen of the DLT within 30 min. Right-sided thoracostomy was performed following hepatectomy, and $300 \mathrm{ml}$ of pleural effusion was drained through the chest tube. Air leakage was observed through the chest tube during positive pressure ventilation. We could not detect and localize abnormal lesion with bronchoscopy. Any gross defect of diaphragm was not observed at operation field. The oxygen saturation of the patient had been consistently maintained at $100 \%$.

Total operation time was $7 \mathrm{~h}$ and estimated blood loss was

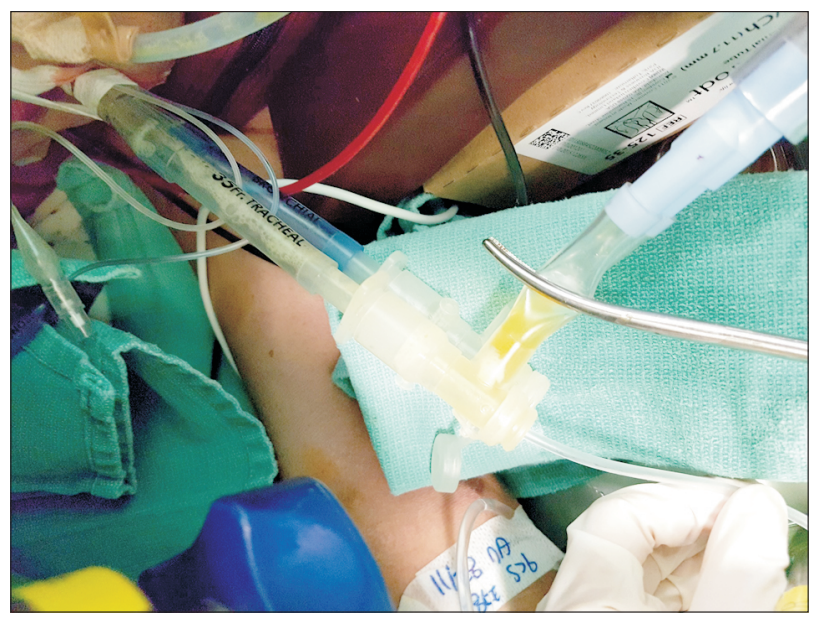

Fig. 2. Serous fluid regurgitated through the right side lumen of double lumen tube.

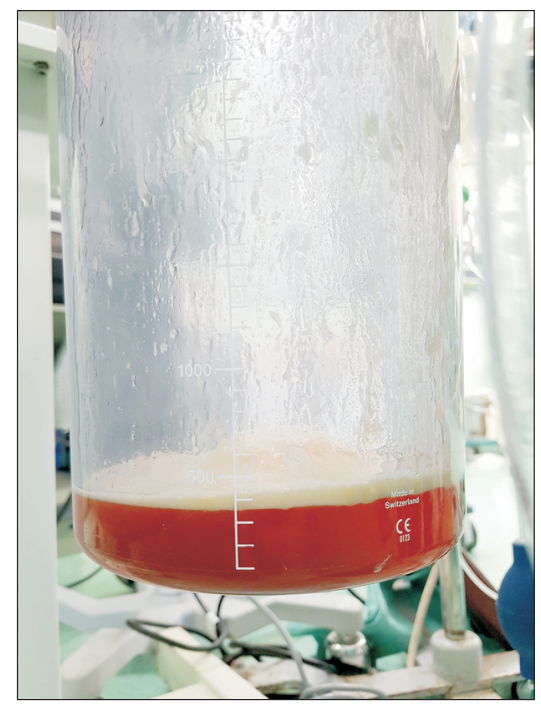

Fig. 3. Large amount of fluid regurgitated through the endotracheal tube.

about 9,000 ml. Nine liters of crystalloid fluid, $550 \mathrm{ml}$ of colloid fluid, 5 units of packed red blood cells and 10 units of fresh frozen plasma were infused. Urine output during the operation was $790 \mathrm{ml}$. Post-operational hemoglobin level decreased to $9.1 \mathrm{~g} / \mathrm{dl}$ after the operation.

The patient was transferred to the intensive care unit (ICU) with intubated state. Laboratory findings of the drained fluid from chest tube and the DLT revealed that it was parapneumonic exudate (pH 7.12, glucose $37 \mathrm{mg} / \mathrm{dl}$, protein $3.31 \mathrm{~g} /$ $\mathrm{dl}$, albumin $1.63 \mathrm{~g} / \mathrm{dl}$, lactate dehydrogenase $346 \mathrm{IU} / \mathrm{L}$, cholesterol $18.2 \mathrm{mg} / \mathrm{dl}$ ). The patient was diagnosed with pneumonia and treated with pleural drainage and antibiotics. The 

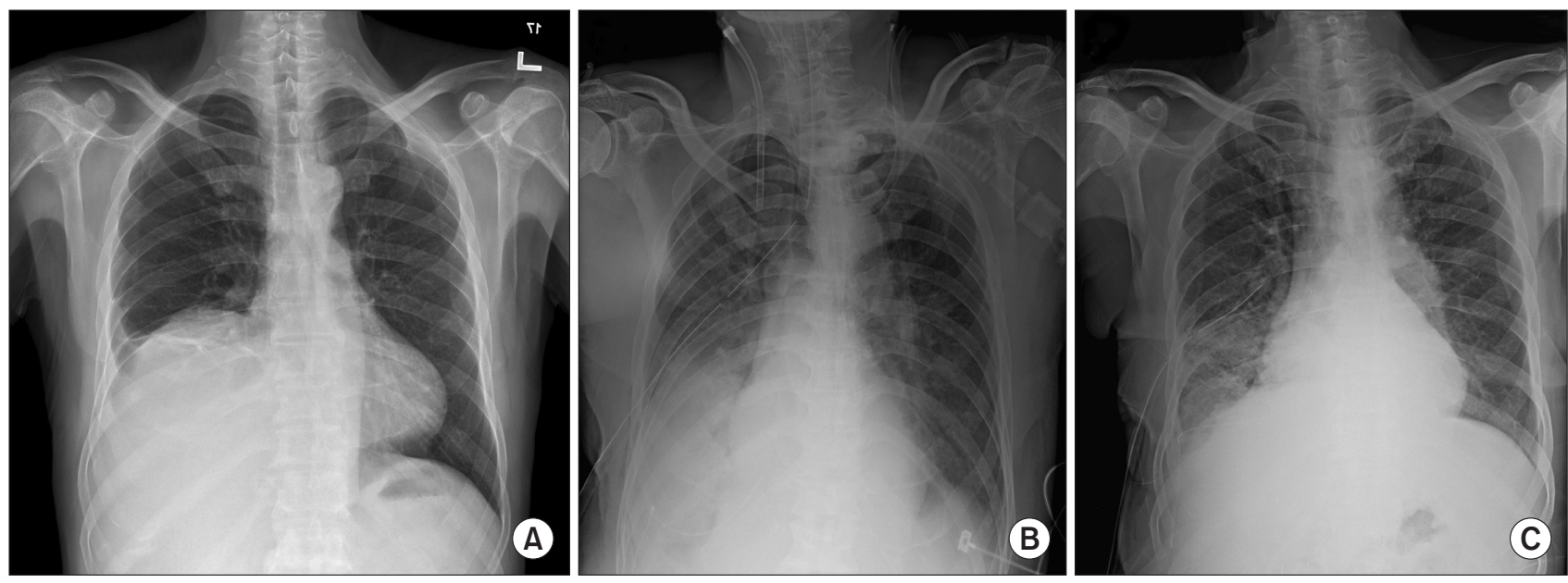

Fig. 4. (A) Preoperative chest radiography showing right costophrenic angle blunting and elevation of diaphragm due to liver mass. (B) Chest radiography on postoperative day 1 showing pleural effusion and pulmonary edema. (C) Chest radiography on postoperative day 5 showing improving of pleural effusion and consolidation of right lung.

volume of fluid drained through the ETT and the chest tube gradually decreased. The patient was extubated on postoperative day 5 and discharged from the ICU (Fig. 4).

\section{DISCUSSION}

An APF is a communication between the pulmonary parenchyma, distal to a segmental bronchus, and the pleural space. Common causes of APFs are invasive thoracic procedure such as lung biopsy, thoracentesis, and thoracic surgery. Other causes include necrotizing pneumonia and abscess, cancer, tuberculosis, infarction, bronchiectasis, trauma or barotrauma [2].

Without appropriate management, APF can lead to persistent air leaks, which are associated with prolonged hospital stays and high morbidity. Conservative managements of APF include ventilator strategies to reduce fistula flow, one lung ventilation, chest tube placement, or endobronchial valves. If these strategies are not successful, further interventions including chemical pleurodesis, autologous blood patch pleurodesis, or unidirectional valve device are needed $[8,9]$.

There were several case reports of APF. The first reported case of APF detected during general anesthesia was described by Woo et al. [10] They suggested that APF developed before surgery due to thoracentesis, whereas our patient did not undergone any invasive procedure of lung. There are several case reports which is not associated with invasive thoracic procedures. El-Sameed et al. [7] reported cases of APF associated with tuberculosis. APF developed during positive pressure ventilation at ICU in a patient with pneumonia was reported by Wiaterek et al. [6]. Our case is different with these three cases because APF developed and detected with pleural effusion regurgitation during the surgery in a patient who had not undergone invasive thoracic procedure.

Any fistula between the pleural space and lung parenchyma, such as BPF or APF, pulmonary edema, and reexpansion pulmonary edema can be considered as a cause of regurgitated fluid through the endotracheal tube. Pulmonary edema was excluded from the differential diagnosis in this case because the regurgitated fluid was different from pink frothy sputum and oxygenation was maintained. In the present case, pleural effusion and consolidation in the right lung were observed on preoperative PET-CT. The patient had no respiratory symptoms preoperatively, and our patient did not undergo lung surgery or any thoracic procedures. Therefore, we considered that an APF occurred during the surgery and pleural effusion was regurgitated through a fistula in the right lung.

In addition, Manipulation of the liver during hepatectomy can facilitate the development of pleural effusion as a result of injury to the diaphragm, obstruction of the thoracic venous or lymphatic systems, or surgical manipulation of the hepatic coronary ligament [11-13]. The massive effusion observed during surgery in our patient could be attributed to hepatectomy.

We assumed that barotrauma due to mechanical ventila- 
tion caused a fistula, with subsequent regurgitation of the pleural effusion. We immediately performed lung isolation with a DLT to protect the opposite side of the lung and reduce air leakage.

In conclusion, we presented a case of APF developed during general anesthesia presenting with massive exudate fluid regurgitated from an endotracheal tube that was managed with bronchial suction, lung isolation, and thoracostomy, and improved without surgical repair of the fistula.

\section{CONFLICTS OF INTEREST}

No potential conflict of interest relevant to this article was reported.

\section{ORCID}

Jun Hyun Kim: https://orcid.org/0000-0002-9466-8399

Sunghyeok Park: https://orcid.org/0000-0001-8604-1716

\section{REFERENCES}

1. Zheng A, Yang X, Ye X, Huang G, Wei Z, Wang J, et al. Bronchopleural fistula after lung ablation: Experience in two cases and literature review. Indian J Cancer 2015; 52 Suppl 2: e41-6.

2. Tsubakimoto M, Murayama S, Iraha R, Kamiya H, Tsuchiya N, Yamashiro T. Can peripheral bronchopleural fistula demonstrated on computed tomography be treated conservatively? A retrospective analysis. J Comput Assist Tomogr 2016; 40: 86-90.

3. Mehta HJ, Malhotra P, Begnaud A, Penley AM, Jantz MA. Treatment of alveolar-pleural fistula with endobronchial application of synthetic hydrogel. Chest 2015; 147: 695-9.
4. Weinreb N, Riker D, Beamis J, Lamb C. Ease of use of watanabe spigot for alveolopleural fistulas. J Bronchology Interv Pulmonol 2009; 16: 130-2.

5. Rosell A, López-Lisbona R, Cubero N, Obiols C, Rivas F, Dorca J. Endoscopic treatment of persistent alveolar-pleural air leaks with a unidirectional endobronchial valve. Arch Bronconeumol 2011; 47:371-3.

6. Wiaterek G, Lee H, Malhotra R, Shepherd W. Bronchoscopic blood patch for treatment of persistent alveolar-pleural fistula. J Bronchology Interv Pulmonol 2013; 20: 171-4.

7. El-Sameed Y, Waness A, Al Shamsi I, Mehta AC. Endobronchial valves in the management of broncho-pleural and alveolopleural fistulae. Lung 2012; 190: 347-51.

8. Akulian J, Feller-Kopman D. The past, current and future of diagnosis and management of pleural disease. J Thorac Dis 2015; 7(Suppl 4): S329-38.

9. Dugan KC, Laxmanan B, Murgu S, Hogarth DK. Management of persistent air leaks. Chest 2017; 152: 417-23.

10. Woo JH, Chung RK, Baik HJ, Kim YJ. Hydrothorax with alveolarpleural fistula mimicking re-expansion pulmonary edema during liver transplantation: a case report. Korean J Anesthesiol 2015; 68: 184-7.

11. Vladov N, Lukanova Ts, Takorov I, Mutafchiyski V, Vasilevski I, Sergeev S, et al. Single centre experience with surgical treatment of hilar cholangiocarcinoma. Chirurgia (Bucur) 2013; 108: 299303.

12. Nobili C, Marzano E, Oussoultzoglou E, Rosso E, Addeo P, Bachellier $\mathrm{P}$, et al. Multivariate analysis of risk factors for pulmonary complications after hepatic resection. Ann Surg 2012; 255: 54050.

13. Yang T, Zhang J, Lu JH, Yang GS, Wu MC, Yu WF. Risk factors influencing postoperative outcomes of major hepatic resection of hepatocellular carcinoma for patients with underlying liver diseases. World J Surg 2011; 35: 2073-82. 